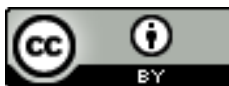

\title{
A UNIVERSIDADE FEDERAL DO SUL DA BAHIA (UFSB) E 0 PROJETO UNIVERSIDADE NOVA: COMO FICAM AS LICENCIATURAS?
}

\author{
THE UNIVERSIDADE FEDERAL DO SUL DA BAHIA (UFSB) AND THE NEW UNIVERSITY \\ PROJECT: HOW ARE TEACHERS LICENSING PROGRAMS? \\ LA UNIVERSIDADE FEDERAL DO SUL DA BAHIA (UFSB) Y EL PROYECTO UNIVERSIDAD \\ NUEVA: ¿CÓMO QUEDAM LAS LICENCIATURAS?
}

\section{Eliana Povoas Pereira Estrela Brito}

RESUMO: O presente trabalho se inscreve no terreno das atuais políticas públicas para a educação superior brasileira focando, neste conjunto, as políticas públicas voltadas à formação de professores. Constitui, como lugar de investigação, o processo de implantação dos Cursos de Licenciaturas Interdisciplinares da Universidade Federal do Sul da Bahia (UFSB). A essa processualidade, questiona-se: Como, no contexto da prática, estão sendo significadas as diretrizes e demais orientações normativas à serviço da organização dos cursos de licenciaturas no Brasil? Quais ações podem ser identificadas como estratégias institucionais voltadas à subversão destes textos políticos? Quais práticas indicam o efetivo atendimento às normativas legais? Em resposta a essas problematizações, a análise identificou a utilização de estratégias institucionais que priorizam o atendimento das dimensões "quantitativas" exigidas pelos textos políticos (distribuição da carga horária da prática como componente curricular e estágio obrigatório) em detrimento das dimensões qualitativas e seus prováveis avanços na perspectiva da formação de professores para atuarem na educação básica.

PALAVRAS-ChaVE: Formação de professores. Políticas educacionais. Universidade nova.

ABSTRACT: This paper is part of the current public policies for Brazilian higher education, focusing on public policies aimed at teacher education. It constitutes, as research place, the process of implantation of the Courses of Interdisciplinary Licenciaturas of the Universidade Federal do Sul da Bahia (UFSB). To this process, the question is: How, in the context of the practice, are the guidelines and other normative guidelines being used in the service of the organization of undergraduate courses in Brazil? What actions can be identified as institutional strategies aimed at subversion of these political texts? Which practices indicate effective compliance with legal regulations? In response to these problematizations, the analysis identified the use of institutional strategies that prioritize the fulfillment of the "quantitative" dimensions required by political texts (distribution of practice hours as a curricular component and mandatory stage) to the detriment of qualitative dimensions and their probable advances From the perspective of teacher training to work in basic education.

KEYWORDS: Teacher training. Public policies. New university.

RESUMEN: El presente trabajo se inscribe en el terreno de las politicas publicas actuales para la educación superior brasileña, enfocando, en este conjunto, en las políticas públicas dirigidas a la formación de profesores. Constituye, como lugar de investigación, el proceso de implantación de los Cursos de Licenciaturas Interdisciplinares de la Universidade Federal do Sul da Bahia (UFSB). A este procedimiento se cuestiona: ¿Como, en el contexto de la práctica, están siendo significadas las directrices y demás orientaciones normativas al servicio de la organización de los cursos de licenciaturas en Brasil? ¿Cuáles acciones pueden ser identificadas como estrategias institucionales dirigidas a la subversión de estos textos políticos? ¿Cuáles prácticas indican la

Submetido em: 20/06/2017 - Aceito em: 09/07/2017 - Publicado em: 09/08/2017.

\begin{tabular}{|l|c|c|c|c|c|} 
(C) Rev. Inter. Educ. Sup. & Campinas, SP & v.3 & n.3 & p.563-581 & set./dez. 2017 \\
\hline
\end{tabular}


efectiva atención a las normativas legales? En respuesta a estas problematizaciones, la análisis identificó la utilización de estrategias institucionales que priorizan la atención a dimensiones "cuantitativas" exigidas por los textos políticos (distribución de carga horaria de práctica como componente curricular y pasantía obligatoria) en detrimento de las dimensiones cualitativas y sus probables avanzos en la perspectiva de la formación de profesores para actuar en la educación básica.

PALABRAS CLAVE: Formación de profesores. Políticas publicas. Universidad nueva.

\section{CONSIDERAÇÕES INICIAIS}

A crise política que marca o atual cenário brasileiro, ao mesmo tempo em que nos impõe a árdua tarefa de discutir e aprofundar as políticas sociais em curso, nos arrasta para um mar de incertezas e de inseguranças perspectivadas pelos anúncios governamentais de cortes, recessões, revogações do ordenamento jurídico ameaçando perdas de direitos sociais duramente conquistados ao longo dos últimos anos. Nesta conjuntura social, sem dúvidas, o campo da educação se fragiliza e todo um conjunto crescente de reivindicações sociais e de disposições legais ficam à deriva desse novo tempo ainda por vir.

Mesmo que dependentes, mais do que em qualquer outro momento, da conjuntura política, o fato é que não podemos deixar de atribuir significados aos avanços conquistados pela educação enquanto um bem público assegurado a todos os brasileiros. Por consequência, torna-se fundamental questionar as formas pelas quais as instituições de ensino vêm respondendo, na prática, aos marcos políticos dos últimos anos. Por mais que os textos políticos ${ }^{2 i i}$ possam propor mudanças, é, no cotidiano efetivamente vivido pelas instituições, que essas definições podem ou não provocar as transformações pretendidas.

Assim colocado, parto do entendimento de que as políticas educacionais dos últimos 13 anos, objetivaram, por um lado, ampliar e interiorizar a oferta do ensino superior brasileiro e, por outro lado, criar estratégias voltadas à sua adaptação aos complexos cenários econômicos, sociais, culturais que caracterizam a nossa contemporaneidade. Desse modo, o presente trabalho se inscreve no terreno das atuais políticas públicas para a educação superior brasileira focando, especialmente, as políticas públicas voltadas à formação de professores constituindo como lugar de investigação o processo de implantação dos Cursos de Licenciaturas Interdisciplinares da Universidade Federal do Sul da Bahia (UFSB).

O objetivo é o de questionar, no "contexto da prática" (BALL, 1992), como a universidade vem respondendo às determinações legais que normatizam os cursos de licenciaturas no

\footnotetext{
${ }^{2}$ Utilizo a expressão "textos políticos", para me referir não apenas ao ordenamento jurídico, mas, também, a depoimentos formais, comentários formais e informais sobre as normativas legais, entrevistas, vídeos, entre outros.

\begin{tabular}{|l|c|c|c|c|c|} 
(C) Rev. Inter. Educ. Sup. & Campinas, SP & v.3 & n.3 & p.563-581 & set./dez. 2017 \\
\hline
\end{tabular}
}


Brasil. A essa processualidade, questiona-se: quais práticas podem ser identificadas como estratégias institucionais que podem alterar ou transformar as políticas originais? Como, no contexto da prática, estão sendo significadas as diretrizes e demais orientações normativas à serviço da organização dos cursos de licenciaturas no Brasil? Quais ações podem ser identificadas como estratégias institucionais voltadas à subversão destes textos políticos? Quais práticas indicam o efetivo atendimento às normativas legais?

Para isto, o presente trabalho analisa o processo de implantação dos Cursos de Licenciaturas Interdisciplinares da mais nova Instituição Federal de Ensino Superior, criada, em 2013, no âmbito do Programa de Apoio a Planos de Reestruturação e Expansão das Universidades Federais (REUNI) ${ }^{3}$ : a Universidade Federal do Sul da Bahia (UFSB). Trata-se, por decorrência, de uma jovem universidade em pleno processo de institucionalização de sua vida acadêmica e administrativa. Esta curta temporalidade de vida institucional acrescida pelos constantes fluxos e refluxos provocados pelos movimentos de institucionalização, seguramente, caracterizam este estudo como uma análise preliminar e provisória do processo em curso. O que não retira, contudo, a relevância e, ainda, a necessidade de um estudo sobre o referido processo de institucionalização em andamento.

O texto encontra-se assim estruturado: inicialmente, apresento uma breve contextualização da arquitetura curricular da UFSB, identificando as influências do "Programa Universidade Nova" na configuração acadêmico-curricular adotada pela instituição. Identifico, alguns complicadores acadêmicos enfrentados pela comunidade acadêmica, em especial, pelos Cursos de licenciaturas, frente ao modelo curricular adotado pela UFSB. Na sequência, situo os Cursos de Licenciaturas Interdisciplinares na estrutura curricular da universidade, dando ênfase especial às dimensões da prática como componente curricular e como estágio obrigatório supervisionado. Privilegio as dimensões da prática no currículo, por entender que as atuais disposições normativas centraram seus esforços nesta dimensão curricular como estratégia central voltada para a qualificação da educação básica no Brasil. Por fim, para fechar o texto, faço algumas considerações que apontam para a importância das lições extraídas da história da educação brasileira, em especial, àquelas a serviço da formação de professores.

\footnotetext{
${ }^{3}$ O Programa REUNI foi instituído pelo Decreto $n^{\circ}$ 6.096, de 24 de abril de 2007, enquanto uma das ações integrantes do Plano de Desenvolvimento da Educação (PDE) atribuindo a educação superior um papel estratégico para o desenvolvimento econômico e social. O REUNI, como já amplamente divulgado, teve como mote estruturador, a expansão e a interiorização da educação superior pública, a partir da reestruturação curricular e acadêmica das Instituições Federais de Ensino Superior (IFES), como uma das condições de adesão ao programa.
}

\begin{tabular}{|l|l|l|l|l|l|} 
(C) Rev. Inter. Educ. Sup. & Campinas, SP & v.3 & n.3 & p.563-581 & set./dez. 2017 \\
\hline
\end{tabular}




\section{AS LICENCIATURAS INTERDISCIPLINARES NA ESTRUTURA ACADÊMICO- CURRICULAR DA UFSB}

A UFSB segue a proposta acadêmico-curricular apresentada pelo "Programa Universidade Nova" que serviu de modelo para o Ministério da Educação (MEC) implantar o REUNI. O modelo proposto por este programa foi apresentado, em 2006, por um de seus idealizadores, Professor Naomar de Almeida Filho, durante o "I Seminário Universidade Nova", na UFBA, em Salvador - BA e, posteriormente, em março de 2007, por ocasião do "II Seminário Universidade Nova", na UnB em Brasília - DF.

Embora, o Plano Orientador da UFSB não faça referências explícitas ao Programa Universidade Nova, o fato é a universidade é o próprio modelo da reestruturação acadêmicocurricular idealizada pela proposta da universidade nova: arquitetura curricular organizada em Ciclos de Formação, com modularidade progressiva (oferecendo certificações independentes a cada ciclo); regime letivo quadrimestral; pluralismo pedagógico e uso intensivo de tecnologias digitais de ensino-aprendizagem. Segundo seus signatários, o Plano Orientador da UFSB foi inspirado pelo Plano Diretor da Universidade de Brasília (UnB), concebido por Darcy Ribeiro e Anísio Teixeira, que previam, no contexto da implantação, a implantação de um sistema de ciclos, em que no primeiro ciclo (sistema básico) o estudante ingressante na graduação teria acesso aos conteúdos básicos e propedêuticos de ciências, humanidades (artes, filosofia e letras) e tecnologia. Para o prosseguimento dos estudos, duas opções eram oferecidas aos estudantes: a faculdade, se a opção fosse a profissionalização ou o instituto, caso optasse por uma carreira científica.

Apesar de o Golpe de 1964 ter interrompido a continuidade desta experiência ainda nos primeiros anos da criação da UnB, o professor Timothy Mulholland, em sua apresentação durante o II Seminário Universidade Nova na UnB, em 2007, afirmou que o modelo, mesmo antes de ser completamente implantado, evidenciava problemas. Entre eles: acúmulo de estudantes em fases profissionais em alguns cursos e a competição e concorrência exagerada dos estudantes nas fases iniciais (formação geral). Situações próximas a essas, foram relatadas, em 1973, pela Universidade Federal da Bahia (UFBA), durante o "Encontro de Reitores das Universidades Públicas e Diretores dos Estabelecimentos Isolados de Ensino Superior", apresentou um diagnóstico conclusivo sobre o fracasso da implantação de ciclos previstos pela a reforma universitária de 1968, no âmbito das diversas universidades brasileiras. Entre os principais problemas à época relatados: excedentes internos, congestionamento nos cursos de maior procura, alto índice de repetência, ausência de disciplinas humanísticas para as áreas de tecnologia e saúde, "standardização" do ensino, fixação de currículo, prazo exagerado (MAZZONI, 2001). 
Mais recentemente, em um artigo intitulado: "Bacharelado interdisciplinar: uma proposta inovadora na educação superior em saúde no Brasil" (2012), os/as professores, professoras Carmen Fontes de Souza Teixeira, Maria Thereza Ávila Dantas Coelho e Marcelo Nunes Dourado Rocha, do Instituto de Humanidades, Artes e Ciências Prof. Milton Santos (IHAC/UFBA), analisam o contexto político-institucional e o processo de elaboração e implantação do Bacharelado Interdisciplinar em Saúde (BIS), na Universidade Federal da Bahia (UFBA), no período 2006-2011. Neste artigo, os autores além de descreverem as condições políticas e institucionais que permitiram, no contexto do projeto "UFBA Nova" (2006), a emergência dos cursos de bacharelados interdisciplinares na UFBA, relatam também os complicadores enfrentados por estudantes e docentes no processo de implantação do curso. Segundo os autores, na perspectiva dos estudantes, os problemas mais agravantes se configuraram pela definição dos critérios e dos procedimentos para ingresso posterior nos Cursos de Progressão Linear (cursos acadêmico-profissionais de segundo ciclo) e, também, pela inquietação, sofrida pelos estudantes, quanto à possibilidade ou não de inserção no mercado de trabalho em saúde, uma vez tendo concluído o curso.

No entendimento da coordenação do curso, os maiores problemas enfrentados se deram "na adaptação do "projeto original" às condições concretas da instituição e as resistências de algumas instâncias superiores da UFBA e de algumas unidades acadêmicas da área de Saúde na operacionalização do curso" (TEIXEIRA, 2011, p. 1639). Por sua vez, para a equipe de professores que atuou no curso, as maiores dificuldades foram decorrentes da "sobrecarga de trabalho derivada do número exíguo de professores em 2009, a turbulência causada pela concomitância entre a elaboração do projeto pedagógico e a implantação do mesmo, as deficiências de infraestrutura e a instabilidade política vivenciada no processo de implantação do Instituto" (TEIXEIRA, 2011, p. 1641).

No âmbito da UFSB, o acesso aos cursos de primeiro ciclo se dá através de duas modalidades: Bacharelados Interdisciplinares (BI) e Licenciaturas Interdisciplinares (LI). Os Cursos de Bacharelados Interdisciplinares são organizados em quatro grandes áreas do conhecimento: saúde, ciências, humanidades e artes. São cursos de graduação plena, com duração mínima de três anos, oferecidos nos campi-sedes, no turno vespertino e noturno. As licenciaturas interdisciplinares são ofertadas somente no noturno e podem ser cursadas nos campi-sedes ou em um dos Colégios Universitários ${ }^{4}$ (CUNIs) que integra a Rede Anísio

\footnotetext{
${ }^{4}$ A entrada dos estudantes na UFSB, a partir da Rede Anísio Teixeira de Colégios Universitários se dá através de um processo diferenciado de seleção. Os estudantes entram na chamada Área Básica de Ingresso para as Licenciaturas Interdisciplinares (ABI-LI). Após concluírem a etapa da formação geral, existe a opção de os estudantes migrarem para um dos Cursos de Bacharelados Interdisciplinares ofertados pela instituição. Caso desejem permanecer nos Cursos de Licenciaturas Interdisciplinares existe, no Plano Orientador, a possibilidade de prosseguirem os estudos no próprio CUNI. No entanto, hoje, a universidade apenas oferece esta possibilidade, aos componentes curriculares que sejam comuns a todas as licenciaturas, como é o caso, dos \begin{tabular}{l|l|l|l|l|l} 
(C) Rev. Inter. Educ. Sup. & Campinas, SP & v.3 & n.3 & p.563-581 & set./dez. 2017 \\
\hline
\end{tabular}
} 
Teixeira ${ }^{5}$. Cinco Cursos de Licenciaturas interdisciplinares são ofertados: Artes e suas tecnologias; Ciências da Natureza e suas tecnologias; Ciências Humanas e Sociais e suas tecnologias; Matemática e Computação e suas tecnologias e Linguagens, Códigos e suas Tecnologias.

A Rede Anísio Teixeira de Colégios Universitários é tecida a partir de cada um dos três campus-sedes da UFSB. O Campus Jorge Amado, situado no Município de Itabuna - BA, sede da reitoria, é aquele que possui a maior quantidade de Colégios Universitários em sua região de abrangência. São quatro CUNIs localizados nos seguintes municípios baianos: Coaraci, Ibicaraí, Ilhéus e Itabuna.

O Campus Paulo Freire, localizado no Município de Teixeira de Freitas - BA, tem, em sua abrangência, apenas um Colégio Universitário que funciona no Município de Itamaraju, em uma das escolas da rede estadual de educação. O Campus Sosígenes Costa, localizado no município de Porto Seguro - BA tem sob sua responsabilidade dois colégios universitários: Um deles, situado no próprio município de Porto Seguro e, o outro, funciona em uma escola da rede estadual, no município de Santa Cruz de Cabrália. Os estudantes dos dois CUNIs, ingressantes da primeira turma, migraram para o campus-sede. Hoje, os CUNIs, pertencentes aos campi de Teixeira de Freitas e de Porto Seguro, possuem somente estudantes da formação geral que entraram, em maio de 2016, na segunda abertura de Edital da UFSB para ingresso nos CUNIs.

Desta forma, ainda que a UFSB esteja apenas no segundo ano de funcionamento de suas atividades acadêmicas, portanto, em pleno processo de institucionalização, muitas das dificuldades relatadas pelos estudos realizados sobre esse modelo acadêmico-curricular, já são possíveis de serem identificadas no cotidiano da instituição: sobrecarga de trabalho para docentes e estudantes acentuada pelo regime letivo quadrimestral e seu curto período para o desenvolvimento dos conteúdos programáticos, atividades extraclasse, etc.; a concorrência exacerbada entre os estudantes com vistas a ingressarem nos cursos de segundo ciclo, em

componentes que integram o chamado tronco comum das licenciaturas. Estes componentes são ofertados desde o campus-sede e transmitido aos CUNIs por meio do uso de tecnologias da comunicação.

${ }^{5}$ De acordo com o Plano Orientador da UFSB, a Rede Anísio Teixeira de Colégios Universitários (Rede CUNI) será implantada em Municípios com mais de 20000 habitantes e com mais de 200 egressos do ensino médio público (EMP) por ano. Os CUNI serão implantados em estabelecimentos da rede estadual de Ensino Médio Público ou de polos regionais de EAD incorporado ao sistema UAB da região. Organizados em rede (institucional e digital), ofertarão programas de ensino descentralizados e mediados por tecnologia de informação e comunicação. Unidades CUNI serão também instaladas nos municípios onde há campus da UFSB, em áreas urbanas de baixa renda que demonstrem alta concentração de egressos do EMP. Unidades CUNI especiais serão também implantadas em quilombos, assentamentos e aldeias indígenas que tenham oferta de EMP e adequada conexão digital.

\begin{tabular}{l|l|l|l|l|l} 
(C) Rev. Inter. Educ. Sup. & Campinas, SP & v.3 & n.3 & p.563-581 & set./dez. 2017
\end{tabular}


especial, os já anunciados cursos de Medicina e de Direito; ausência de diretrizes claras para a progressão aos cursos de segundo ciclo, indefinição relativa ao rol de cursos que serão ofertados no segundo ciclo, entre outros fatores que contribuem para um clima de relativa instabilidade e desassossego institucional.

Cabe ressaltar que, embora os critérios a serem utilizados para o ingresso dos estudantes aos cursos de segundo ciclo ainda não estejam suficientemente esclarecidos para a comunidade acadêmica em geral, é ponto pacífico que o índice de rendimento obtido em cada um dos componentes curriculares cursados seja decisivo para a disputa das vagas que, por óbvio, serão menores do que o demandado pelo universo de estudantes. Outro fator a ser considerado é o coeficiente de rendimento nas chamadas áreas de concentração ou trajetórias pré-profissionais, índices presentes na formação específica de cada um dos cursos de bacharelados. Neste sentido, a disputa entre os estudantes pela obtenção de melhores pontuações (notas) enfraquece princípios como o da solidariedade e o da cooperação, exaltados pela instituição em seu Plano Orientador.

Neste cenário onde a meritocracia será definidora do futuro profissional dos estudantes da UFSB, não restam dúvidas de que, em especial, os estudantes que optaram pelas licenciaturas interdisciplinares terão muito menos chances de entrarem nos cursos profissionalizantes mais concorridos na instituição. Isso porque, embora o plano orientador da universidade anuncie que "concluintes de BI e LI que desejarem ingressar no Segundo Ciclo, visando à formação em carreiras profissionais, serão avaliados com base no aproveitamento no Primeiro Ciclo" (UFSB, 2014, p.13), não existem disposições institucionais que estabeleçam critérios justos para cursos de naturezas diferenciadas, como são os cursos de licenciaturas interdisciplinares.

$\mathrm{Na}$ tentativa de criar supostas condições de igualdade na disputa dos cursos de segundo ciclo, os currículos das licenciaturas tendem a ser o mais similar possível ao currículo dos cursos de bacharelados. Esse tipo de lógica utilizada pela instituição, ainda que contemple as expectativas de uma grande parte dos estudantes das licenciaturas, suprime as singularidades de um curso de formação de professores que tem uma natureza acadêmico-profissional já demarcada em ciclo básico. Fora isto, as licenciaturas são cursos, ofertados apenas no turno noturno, para um universo de estudantes, majoritariamente, trabalhadores. Neste sentido, seria ingênuo o pensamento de que a oferta de componentes curriculares comuns as licenciaturas e aos bacharelados se constitua em dispositivo produtor das condições de igualdade nas disputas acadêmicas travadas entre estudantes dos bacharelados e os das licenciaturas.

Importa sublinhar que, por ocasião dos seminários de apresentação da Proposta de Universidade Nova, as licenciaturas, ainda que rapidamente mencionadas, estavam previstas aos moldes do velho e criticado Esquema 3+1. A ideia divulgada, à época, era a de que, os 
estudantes, após concluírem o ciclo básico, cursariam componentes pedagógicos da formação específica, podendo, inclusive, aproveitar créditos do ciclo básico, e estariam aptos (sic!) a lecionarem na educação básica. Ou seja, a proposta da universidade nova incorporava concepções ultrapassadas no campo da formação de professores ao tentar reavivar o famigerado Esquema 3+1 (ou +2 ).

Mesmo considerando-se que o foco da reforma universitária pretendida pelo REUNI tivesse o currículo dos cursos de graduação como alvo (estruturas curriculares mais flexíveis, interdisciplinares, inovadores, percursos acadêmicos singulares, etc.), o fato é que as discussões levantadas pela proposta da Universidade Nova ficaram centradas nos cursos de bacharelados interdisciplinares e suas supostas contribuições para o cenário universitário brasileiro.

No Plano Orientador da UFSB, as licenciaturas são previstas para os concluintes da Formação Geral na Área Básica de Ingresso (ABI), tanto nos Institutos de Humanidades, Artes e Ciências (IHACs) situados nos campi, quanto nos Colégios Universitários (CUNIs). "Com aproveitamento de infraestrutura de Tecnologia da Informação e Comunicação (TIC) implantada e operante, as Licenciaturas Interdisciplinares utilizam Polos Presenciais da Universidade Aberta do Brasil (UAB) a serem implantados nos CUNIs" (UFSB, 2014, p.23).No entanto, elas ganharam maior visibilidade institucional, a partir do acordo de cooperação firmado, em fevereiro de 2016, entre a universidade e a Secretaria Estadual de Educação do Estado da Bahia, visando à implantação dos chamados "Complexos Integrados de Educação" ${ }^{6 "}$ (CIEs) da rede estadual de ensino médio do Sul da Bahia.

\section{A ORGANIZAÇÃO CURRICULAR DAS LICENCIATURAS INTERDISCIPLINARES DA UFSB}

Grosso modo, pode-se dizer que as licenciaturas interdisciplinares da UFSB possuem uma arquitetura curricular organizada em duas etapas: Formação Geral e Formação Específica. A Formação geral compreende os três primeiros quadrimestres letivos e são comuns ao

\footnotetext{
${ }^{6}$ No âmbito do Convênio Secretaria Estadual de Educação (SEC- BA) e UFSB, a universidade destaca a criação de Complexos Integrados de Educação (CIE) inicialmente em três das escolas da rede estadual de ensino que mantêm um CUNI. Cada CIE será composto por: Centro de Ensino Médio Integral (CEMI); Centro Noturno de Ensino (CNE, CENEB - Centro Noturno de Educação da Bahia); Centro de Formação Docente Continuada (CFDoC) e Colégio Universitário (CUNI). Trata-se, portanto, de um Centro que reúne ensino superior, formação docente e cogestão de escolas de ensino médio e ensino noturno, mediante forte ligação das práticas pedagógicas neles realizadas, juntamente com a formação de professores na UFSB, em suas LIs. A gestão administrativa permanece sob responsabilidade da SEC, sendo compartilhada e assessorada pela UFSB. A gestão das práticas pedagógicas no CIE passa ao âmbito da UFSB, compartilhada e assessorada pela SEC. A equipe de gestão administrativa, sob a responsabilidade da SEC, pode ser complementada pela UFSB no que se refere ao apoio à docência.
}

\begin{tabular}{l|l|l|l|l|l|} 
(C) Rev. Inter. Educ. Sup. & Campinas, SP & v.3 & n.3 & p.563-581 & set./dez. 2017
\end{tabular}


currículo de formação de todos os estudantes da instituição, ou seja, aos quatro Bacharelados interdisciplinares e às cinco Licenciaturas Interdisciplinares.

No conjunto, a formação geral totaliza uma carga horária de 900 horas, 300 horas, por cada um dos quadrimestres, distribuídas por componentes curriculares que centram suas temáticas nos seguintes campos de conhecimento: língua portuguesa (150 horas), língua inglesa (90 horas), matemática e computação (180 horas), universidade e sociedade (180 horas) e, um componente curricular, fora dos eixos temáticos, denominado de experiências do sensível (60 horas). Para além destes componentes curriculares obrigatórios a todos os estudantes da UFSB, os licenciandos devem cursar o componente curricular: Campo da Educação: saberes e práticas (60 horas) e, mais 120 horas em componentes curriculares que representem culturas complementares à área específica de formação de seu curso. Por exemplo, um estudante da Licenciatura Interdisciplinar em Humanidades e Ciências Sociais poderá cursar essa carga horária em atividades curriculares ofertadas pelos Cursos de Bacharelados ou de Licenciaturas em uma das áreas específicas: ciências, artes, saúde, matemática ou linguagem.

$\mathrm{Na}$ formação específica, embora, cada uma das Licenciaturas tenha construído desenhos curriculares singulares, no geral, esta etapa de formação é composta por componentes curriculares obrigatórios, componentes curriculares optativos, componentes curriculares livres, componentes curriculares do chamado tronco comum das licenciaturas e estágio supervisionado. As práticas como componentes curriculares, tal como propostas pelas DCNS (BRASIL, CNE-CP N², 2015), encontram-se previstas nos currículos dos cursos, fazendo parte do conjunto dos componentes curriculares de natureza obrigatória. As atividades complementares, com carga horária de 200 horas, integram o currículo das cinco licenciaturas interdisciplinares.

Anterior a homologação das Diretrizes Curriculares Nacionais para a Formação Inicial e Continuada dos Profissionais do Magistério da Educação Básica - Parecer CNE/CP N²/2015, em 25/06/2015, a universidade trabalhava com a ideia de que as duas modalidades de Cursos, ofertados pela UFSB, obedecessem a um mesmo prazo mínimo de integralização, ou seja, 3 anos ou 9 quadrimestres letivos. Essa condição, de acordo com os gestores da UFSB, seria um critério importante para que os estudantes das Licenciaturas e dos Bacharelados Interdisciplinares pudessem concorrer, em um mesmo prazo de tempo, aos cursos de segundo ciclo. 
No entanto, como as licenciaturas interdisciplinares não possuem legislação própria ${ }^{7}$, a UFSB foi obrigada a atender a carga horária prevista pelo Parecer CNE/CP №2/2015, fixando em, no mínimo, 3200 horas a integralização dos cursos de licenciaturas. Com isto, os Cursos de Licenciaturas passaram a ter um prazo mínimo de integralização, de 10 quadrimestres letivos contabilizando um quadrimestre a mais do que o previsto para os Cursos de Bacharelados Interdisciplinares.

O chamado "tronco comum" das licenciaturas se limita a agrupar componentes curriculares que atendam às disposições legais previstas para os cursos de formação de professores. Neste sentido, a seleção dos componentes curriculares foi orientada pelo inciso IV, § $2^{\circ}$, do art. 13 do Parecer CNE/CP N²/2015, quando diz:

\begin{abstract}
Os cursos de formação deverão garantir nos currículos conteúdos específicos da respectiva área de conhecimento ou interdisciplinares, seus fundamentos e metodologias, bem como conteúdos relacionados aos fundamentos da educação, formação na área de políticas públicas e gestão da educação, seus fundamentos e metodologias, direitos humanos, diversidades étnico-racial, de gênero, sexual, religiosa, de faixa geracional, Língua Brasileira de Sinais (Libras), educação especial e direitos educacionais de adolescentes e jovens em cumprimento de medidas socioeducativas.
\end{abstract}

Por consequência, oito componentes curriculares integram o tronco comum: Bases Epistemológicas da Educação (60h); Políticas Públicas Educacionais e Gestão Escolar (60h); Educação e Direitos Humanos (30h); Educação Ambiental e Sustentabilidade (30h); Educação e Relações Étnico-raciais (30h); Educação Inclusiva (30h), Educação, Gênero e Diversidade Sexual (30 horas) e Libras (60h), cujo conjunto, totaliza 330 horas. Esta decisão institucional faz com que as licenciaturas cumpram com os requisitos mínimos exigidos pelos dispositivos legais, encobrindo algumas lacunas criadas por um modelo de licenciatura que mais se assemelha às extintas licenciaturas curtas.

\footnotetext{
${ }^{7}$ A Portaria n $\mathrm{n}^{\mathrm{O}}$ 40, de 31 de agosto de 2015 (MEC/SEB), publicada no DOU de 23/09/2015, institui o Grupo de Trabalho das Licenciaturas Interdisciplinares, GT-LI's, com as seguintes atribuições: I. Coletar e sistematizar as contribuições das IES, em harmonia com as Diretrizes Curriculares Nacionais para a Formação Inicial e Continuada dos Profissionais do Magistério da Educação Básica, em especial seu Art. 24, no qual consta que os cursos de licenciatura, organizados em áreas interdisciplinares, serão objeto de regulamentação suplementar; II. Elaborar proposta de adequações aos instrumentos de avaliação para fins de regulamentação das LI's e similares; III. Assessorar o MEC na construção, consolidação, difusão e institucionalização desses cursos no país e IV. Sugerir aperfeiçoamentos para avanços contínuos desses cursos. Compõem a referida comissão dois professores - gestores da UFSB: Professor Naomar Almeida Filho (Reitor pró'-tempore) e Professor Álamo Pimentel, à época, Diretor de Ensino da Pró-Reitoria de Gestão Acadêmica (PROGEAC/UFSB). Embora, a Portaria tivesse previsto um prazo de 180 dias para que a comissão propusesse ao MEC os subsídios para o ordenamento dos referidos cursos, até então, não existe a homologação de legislação específica para os Cursos de Licenciaturas Interdisciplinares.

\begin{tabular}{|l|c|c|c|c|c|} 
(C) Rev. Inter. Educ. Sup. & Campinas, SP & v.3 & n.3 & p.563-581 & set./dez. 2017
\end{tabular}
}


É necessário ressaltar também, o fato de que, com exceção do estágio curricular obrigatório, todos os demais componentes curriculares possuem um percentual de $20 \%$ de atividades extra classe previstos na integralização de suas cargas horárias. Essa "inovação curricular" se configura como uma estratégia administrativa utilizada para favorecer e adequar a opção, feita pela UFSB, de adotar um regime letivo quadrimestral. Neste sentido, embora as DCNs orientem a distribuição das 3200 horas, distribuindo-as em um prazo mínimo de 8 semestres ou 4 anos, o Parecer é omisso quanto a outras possibilidades de organização do trabalho acadêmico, o que abre brechas para que diferenciadas interpretações possam ocorrer.

Assim, se, por um lado, a UFSB pode dizer que obedece às determinações legais relativas à carga horária mínima estipulada pelas DCNs, por outro lado, e sob a justificativa da "inovação", não cumpre com o tempo de formação estipulado pelo mesmo dispositivo legal.

Tempo esse que, por óbvio, não pode ser entendido como um tempo linear e cronológico em que bastasse o seu cumprimento "ao pé da letra". Antes, trata-se de um tempo de formação que interfere no agir docente e discente, que é desalinhado em relação ao tempo cronológico, posto tratar-se de uma noção temporal que contemple o necessário exercício para o desenvolvimento do pensamento, da reflexão crítica e da enunciação com vistas à construção da autonomia, como nos ensinou Paulo Freire, em diversos estudos.

Decorre daí, no mínimo, dois questionamentos inevitáveis. Um deles, guiado pela lógica simplista do mero atendimento ao texto legal, qual seja, o acréscimo de um quadrimestre (72 dias letivos), embora, ocorra no quarto ano civil do curso, atende ao prazo mínimo estipulado pelas DCNs? O outro, orientado pelo tempo pedagógico necessário para a construção da autonomia na docência, questiona se, em termos qualitativos, dez quadrimestres podem ser equiparados a oito semestres?

\section{A PRÁtica no eStágIO SUPERVISIONAdo no CURRículo das LICENCIATURAS INTERDISCIPLINARES}

O estágio supervisionado no currículo das Licenciaturas Interdisciplinares da UFSB tem seu início no quarto quadrimestre letivo, logo após o término da formação geral, percorrendo toda a trajetória de formação dos futuros professores. Integram o currículo na condição de componentes curriculares, ofertados quadrimestralmente, com uma carga horária de 60 horas, perfazendo um total de, no mínimo, 400 horas, ao término do curso.

De acordo com o documento intitulado: "Diretrizes, documentos e bases legais para o Estágio Supervisionado nas Licenciaturas Interdisciplinares da UFSB - proposta - versão 1" (DEA/PROGEAC/UFSB, maio, 2016), o estágio "está pensado em três etapas centradas nas/nos estudantes, com caráter de trabalho coletivo: 1) observação ativa, levantamento de 
possibilidades e elaboração de projeto; 2) execução do projeto; 3) avaliação e divulgação dos resultados". Nas discussões coletivas da equipe docente responsável pelos estágios das licenciaturas, a ideia tem sido a de causar rupturas com uma concepção etapista para o desenvolvimento dos estágios. No entanto, o calendário acadêmico quadrimestral, ao mesmo tempo em que pulveriza e fragmenta o ano letivo, já que possui períodos de recesso entre os quadrimestres, potencializa a desarticulação com os calendários letivos das escolas das redes públicas do Estado da Bahia.

Por efeito, o estágio supervisionado possui uma carga horária quadrimestral de 60 horas distribuídas em tempo/escola e tempo/universidade. Essa partilha vem favorecendo a formação dos futuros professores, apesar de descaracterizar a natureza do estágio quanto ao tempo de permanência do estudante em seu futuro local de trabalho à medida que abre tempos/espaços onde, para além das problematizações extraídas das experiências vividas nas escolas, as dimensões relativas à didática, às metodologias e práticas de Ensino sejam, minimamente, trabalhadas.

Convém lembrar que a Lei 13.005/2014, referente ao Plano Nacional de Educação (PNE), propõe como uma das estratégias para a formulação da política nacional de formação dos profissionais do magistério (Meta 15),

\begin{abstract}
promover a reforma curricular dos cursos de licenciatura e estimular a renovação pedagógica, de forma a assegurar o foco no aprendizado do(a) aluno(a), dividindo a carga horária em formação geral, formação na área do saber e didática específica e incorporando as modernas tecnologias de informação e comunicação, em articulação com a base nacional comum dos currículos da educação básica [...]. (Grifo nosso).
\end{abstract}

As dimensões acerca da organização do trabalho pedagógico, das metodologias e das estratégias de ensino e avaliação, por exemplo, embora estejam previstas enquanto "prática como componente curricular", fazem com que os estudantes iniciam seus estágios sem que conheçam essas noções básicas. Aqui é importante frisar que as concepções entre prática como componente curricular e estágio supervisionado, encontram-se, claramente, descritas pelo Parecer CNE/CES nº 15/2005, quando diz:

(...) a prática como componente curricular é o conjunto de atividades formativas que proporcionam experiências de aplicação de conhecimentos ou de desenvolvimento de procedimentos próprios ao exercício da docência. (..). As atividades caracterizadas como prática como componente curricular podem ser desenvolvidas como núcleo ou como parte de disciplinas ou de outras atividades formativas. Isto inclui as disciplinas de caráter prático relacionadas à formação pedagógica, mas não aquelas relacionadas aos fundamentos técnico-científicos correspondentes a uma determinada área do conhecimento. Por sua vez, o estágio supervisionado. Por sua vez, o estágio supervisionado é um conjunto de atividades de formação, realizadas sob a supervisão de docentes da instituição formadora, e acompanhado 
por profissionais, em que o estudante experimenta situações de efetivo exercício profissional.

Sublinhe-se que as problemáticas que envolvem as dimensões da prática nos cursos de formação de professores não são atuais. Antes, desde a década de 1980, que a literatura especializada da área vem problematizando a necessidade de romper com a correlação, historicamente construída, entre prática e teoria, onde o estágio era concebido como o tempo/espaço propício para a aplicação prática (técnica) das teorias estudadas no processo de formação. No Brasil, os estudos de FREIRE (1996), as traduções dos trabalhos de SCHÖN (1992); SACRISTAN (1999); TARDIF (1991); NÓVOA (1992), entre outros, em muito contribuíram para romper com a cultura da aplicabilidade presente nas concepções de cunho tecnicistas nas licenciaturas. As problemáticas trazidas por estes e outros estudiosos da área, deram relevo às problematizações acerca da prática reflexiva, do currículo como espaço de ação, sobre das competências necessárias à docência e da importância das experiências vivenciadas pelo estudante para o exercício profissional dos futuros professores.

Seguindo as lições dos "Ciclos de políticas", trabalhadas por BALL e BOWE (1992), é possível afirmarmos que a literatura especializada na área e, seus desdobramentos na arena educacional brasileira, interferiu no "contexto da influência" sobre as normativas legais voltadas à formação de professores, desde o ano 2000. No entanto, como os mesmos autores afirmam, é no "contexto da prática (BALL; BOWE, 1992) que estes textos sofrem interpretações e recriações, podendo ou não, contribuírem para que efetivas mudanças ocorram.

Refiro-me aqui, muito especialmente, ao Parecer CNE/CP n ${ }^{\circ}$ 9/2001, Parecer CNE/CP $n^{\circ}$ 28/2001 e Parecer CNE/CES no 15/2005, que, em seus textos, já destacavam a importância da ampliação dos tempos/espaços voltados para o conhecimento e análise das dimensões pedagógicas, não necessariamente com inserção no contexto escolar, na perspectiva da prática como componente curricular, mas exigindo que o estágio obrigatório se caracterizasse por um tempo de permanência in loco do estudante-estagiário em seu futuro local de trabalho, sob a supervisão de um professor qualificado na área.

Se faz necessário dizer que, apesar de alguns significativos avanços conquistados, a luta pela valorização da prática, entendida como um divisor de águas entre os cursos de licenciaturas e os cursos de bacharelados, permanece acirrada, tanto na arena discursiva das instituições formadoras, quanto nos textos das políticas mais amplas. Assim, mais de dez anos após a publicação do Parecer CNE/CP n 9/2001; Parecer CNE/CP n' 28/2001 e do Parecer CNE/CES n $n^{\circ} 15 / 2005$, a prática pedagógica, enquanto um dispositivo produtor da docência, retoma sua centralidade na Resolução $\mathrm{CNE} / \mathrm{CP} \mathrm{n}^{\circ} 2 / 2015$, que define as Diretrizes 
Curriculares Nacionais para a formação de professores para a educação básica, instituindo mudanças significativas voltadas à necessária singularização das licenciaturas.

$\mathrm{Na}$ tentativa de colocar um ponto final na oferta de Cursos de Licenciaturas curtas (média, em três anos) e possíveis complementações para os Cursos de Bacharelados, ou vice-versa, configurando o Esquema $3+1$, as DCNs atribuíram radical centralidade à prática pedagógica, o que levou a ampliação da carga horária de integralização das licenciaturas para 3200 horas e exigiu o prazo de quatro anos letivos. Assim, do total da carga horária prevista, 400h devem ser de prática como componente curricular, distribuídas ao longo do processo formativo, e 400h devem ser dedicadas ao estágio supervisionado, na área de formação e atuação na educação básica.

Neste ponto é preciso compreender que se, por um lado, os dispositivos legais interferem nos arranjos e práticas curriculares, por outro, as práticas curriculares recriam significados, reinterpretam e disputam sentidos, produzem políticas, pois,

\begin{abstract}
os profissionais que atuam no contexto da prática [escolas, por exemplo] não enfrentam os textos políticos como leitores ingênuos, eles vêm com suas histórias, experiências, valores e propósitos (...). Políticas serão interpretadas diferentemente uma vez que histórias, experiências, valores, propósitos e interesses são diversos. A questão é que os autores dos textos políticos não podem controlar os significados de seus textos. Partes podem ser rejeitadas, selecionadas, ignoradas, deliberadamente mal-entendidas, réplicas podem ser superficiais etc. Além disso, interpretação é uma questão de disputa. Interpretações diferentes serão contestadas, uma vez que se relacionam com interesses diversos, uma ou outra interpretação predominará, embora desvios ou interpretações minoritárias possam ser importantes. (BOWE, 1992, p.22, apud MAINARDES, 2006, p.56).
\end{abstract}

Ao valorizar as ações dos professores e demais atores diretamente envolvidos nas práticas institucionais, esta abordagem abre brechas para que possamos, enquanto sujeitos que interferem diretamente nas formas pelas quais os textos políticos adquirem materialidade no cotidiano institucional, permanecer na luta para que as licenciaturas possam ter a sua implementação com qualidade socialmente referendada.

\title{
LIÇõES EXTRAÍDAS DA HISTÓRIA: NOTAS PARA FECHAR O TEXTO
}

Para fechar o texto, importa lembrar, logo de saída, o fato de que a UFSB é uma nova universidade que se institucionaliza a partir dos princípios acadêmicos-curriculares que caracterizam a proposta que ficou conhecida como "Universidade Nova", cujo objetivo central é a reestruturação da arquitetura acadêmica do ensino superior no Brasil. Esta proposta, tal como colocado anteriormente, serviu de modelo para a elaboração do Programa REUNI, apresentado às universidades federais, pelo Ministério da Educação, em 2007.

\begin{tabular}{l|l} 
n.3 & p.563-581
\end{tabular}

set./dez. 2017 
Disseminando um discurso desqualificador da educação superior pública brasileira, o REUNI centrou suas críticas na organização curricular dos cursos de graduação, descritos como fragmentados, desarticulados e defasados em relação às demandas contemporâneas. Nesta esteira discursiva, postulou-se a favor da necessidade de que mudanças curriculares profundas e urgentes ocorressem, pois,

a manutenção da atual estrutura curricular de formação profissional e acadêmica, ao reforçar as lógicas da precocidade profissional e da compartimentação do saber, coloca o país em risco de isolamento nas esferas científica, tecnológica e intelectual de um mundo cada dia mais globalizado e inter-relacionado. (BRASIL, Portaria $n^{\mathbf{o}}$ $552 \mathrm{SESu}, 2007$, p.10).

Embora, o REUNI, tenha apresentado diretrizes voltadas à diversificação das modalidades de cursos de graduação induzindo, desta maneira, novos arranjos na estrutura acadêmica, a grande maioria das instituições que aderiram ao REUNI, não sem resistência por parte das comunidades acadêmicas, acabou por apresentar propostas que se limitaram a expansão ${ }^{8} \mathrm{da}$ oferta de vagas de graduação, tanto nos cursos existentes, quanto pela criação de novos cursos.

No entanto, capturadas pelo discurso das invocações curriculares, 15 universidades federais iniciaram, em 2006, a oferta de cursos interdisciplinares como inovações curriculares propostas em suas adesões ao Programa. As licenciaturas interdisciplinares emergem neste contexto como uma invenção político-pedagógica pautada pela reforma universitária apresentada pelo REUNI.

Vários estudiosos (CORREIA (2009); LÉDA; MANCEBO (2009); LEHER(2013); LIMA (2009), entre outros), ao analisarem as bases de fundamentação teórica e política do REUNI, fizeram duras críticas a adoção de sistema de ciclos e da promoção da mobilidade discente, inspirado pela reforma universitária europeia conhecida como "processo de Bolonha" e seus desdobramentos na fragmentação da formação profissional que, no limite, potencializa o crescente ajustamento das universidades às regras do mercado alterando substantivamente o papel e funções sociais da universidade enquanto bem público.

\footnotetext{
${ }^{8}$ De acordo com o documento: "REUni 2008 - Relatório de Primeiro Ano" (MEC / SESu / DIFES, out. 2009), das 53 universidades federais que aderiram ao REUNI, 26 apresentaram projetos com componentes de inovação, agrupados, neste relatório, da seguinte maneira: Formação em ciclos (geral, intermediário, profissional ou de pós-graduação); Formação básica comum (ciclo básico ou por grandes áreas); Formação básica em uma ou mais das Grandes Áreas: Saúde, Humanidades, Engenharias e Licenciaturas; Bacharelados Interdisciplinares em uma ou mais das Grandes Áreas: Ciências, Ciências Exatas, Ciência e Tecnologia, Artes, Humanidades, Saúde; Bacharelados com dois ou mais itinerários formativos.

(C) Rev. Inter. Educ Sup $\quad$ Campinas, SP

\begin{tabular}{l|l|l} 
n.3 & p.563-581 & set./dez. 2017
\end{tabular}
}


Se, estas dimensões já se mostraram problemáticas em suas tentativas de implantação no decurso da história da educação brasileira, a situação, quando perspectivada no âmbito da formação de professores, torna-se, no mínimo, temerária. Apesar da UFSB estar no início de sua caminhada institucional, ao se inscrever nos pressupostos da "universidade nova" e colocar os Cursos de Licenciaturas Interdisciplinares na mesma racionalidade que preside os Cursos de Bacharelados Interdisciplinares, as descaracteriza enquanto um curso de formação profissional que tem por função social e política contribuir decisivamente na melhoria da qualidade da educação básica no Brasil.

Não se trata, por efeito, de deixar de reconhecer as potencialidades que um curso de formação de professores possa vir a ter a partir de uma perspectiva curricular que crie espaços/tempos de aproximações entre os campos de conhecimentos elementares para o complexo exercício da docência. Não se trata, também, de uma reivindicação saudosista aos orientadores pedagógicos e curriculares que estruturam as licenciaturas ditas "tradicionais", suas seleções, distribuições e hierarquizações dos conhecimentos. Não se trata, tão pouco de tecer questionamentos com bases meramente jurídicas quanto ao atendimento ou não dos marcos regulatórios. Antes, trata-se de seguir as lições extraídas da história da educação pública brasileira e se suas políticas, das lutas travadas pelos professores em defesa da valorização e qualificação de seus processos de formação. Lutas essas que recusam por inteiro o retorno das licenciaturas curtas, que não admitem supostos mascaramentos do Esquema 3+1, que reivindicam o espaço da prática como nuclear em seus processos formativos.

Por fim, volto aos questionamentos colocados como questões-desafios deste trabalho, para responder, ainda que de forma provisória, posto que as licenciaturas ainda estão em fase de implantação, que a UFSB "obedece" às dimensões quantitativas atribuídas pelas normativas vigentes (quantitativos de horas, suas distribuições entre as dimensões curriculares exigidas formalmente), no entanto, na mesma operação em que presta obediência às normas vigentes, subverte-as, em nome da inovação, da singularidade e originalidade atribuídas a esses cursos.

As ações que reivindicam uma formação de professores que não apenas cumpra com as "constatações" objetivas das avaliações externas, mas que considerem os tempos/espaços necessários para que aprendizagens significativas possam ocorrer, têm sido arduamente defendidas por estudantes e professores dos cursos. Estas dimensões se, devidamente consideradas, remetem a sérias revisões na organização curricular dos Cursos de Licenciaturas Interdisciplinares da UFSB. 


\section{REFERÊNCIAS}

BALL, Stephen. Diretrizes políticas globais e relações políticas locais em educação. Currículo sem fronteiras, Porto Alegre, v.1, n.2, p. 99-116, jul./dez. 2001. Disponível em: <http://www.curriculosemfronteiras.org/vol1iss2articles/ball.pdf >. Acesso em: 12 maio 2016.

BALL, Stephen; BOWE, Richard. Subject departments and the "implementation" of National Curriculum policy: an overview of the issues. Journal of Curriculum Studies, London, v. 24, n. 2, p. 97-115, 1992.

BRASIL. Lei n ${ }^{\circ} 13.005$, de 25 de junho de 2014. Aprova o Plano Nacional de Educação PNE, e dá outras providências. Diário Oficial da União, Brasília, DF, 26 jun. 2014. Disponível em: <http://www.planalto.gov.br/ccivil_03/_Ato20112014/2014/Lei/L13005.htm>. Acesso em: 12 maio 2016.

BRASIL. Ministério da Educação. Parecer CNE-CES n 15, de 02 de fevereiro de 2005. Solicitação de esclarecimento sobre as Resoluções CNE/CP n ${ }^{\circ}$ s 1/2002, que institui Diretrizes Curriculares Nacionais para a Formação de professores da Educação Básica, em nível superior, curso de licenciatura, de graduação plena, e 2/2002, que institui a duração e a carga horária dos cursos de licenciatura, de graduação plena, de Formação de Professores da Educação Básica, em nível superior. Brasília: Conselho Nacional de Educação, 2005. Disponível em: <http://portal.mec.gov.br/cne/arquivos/pdf/pces0015_05.pdf>. Acesso em: 15 maio 2016.

BRASIL. Ministério da Educação. Parecer CNE-CP nº 02, de 09 de junho de 2015. Institui Diretrizes Curriculares Nacionais para a Formação Inicial e Continuada dos Profissionais do Magistério da Educação Básica. Brasília: Conselho Nacional de Educação, 2015. Disponível em: <http://portal.mec.gov.br/index.php?option=com_docman\&view= download\&alias=17719-res-cne-cp-002-03072015\&category_slug=julho-2015-pdf\&Itemid =30192> . Acesso em: 20 julho 2016 .

BRASIL. Ministério da Educação.Resolução CNE-CP nº 02, de 19 de fevereiro de 2002. Institui a duração e a carga horária dos cursos de licenciatura, de graduação plena, de formação de professores da educação básica em nível superior. Brasília. Conselho Nacional de Educação, 2002. Disponível em: <http://portal.mec.gov.br/cne/arquivos/pdf/ CP022002.pdf >. Acesso em: 16 maio 2016.

BRASIL. Ministério da Educação. Parecer CNE-CP nº 09, de 08 de maio de 2001. Institui diretrizes curriculares nacionais para a formação de professores da educação básica, em nível superior, curso de licenciatura de graduação plena Brasília. Conselho Nacional de Educação, 2001. Disponível em: <http://portal.mec.gov.br/cne/arquivos/pdf/009.pdf> Acesso em: 28 maio 2016. 
BRASIL. Ministério da Educação. Parecer CNE-CP nº 28, de 02 de outubro de 2001. Dá nova redação ao Parecer CNE/CP 21/2001, que estabelece a duração e a carga horária dos cursos de Formação de Professores da Educação Básica, em nível superior, curso de licenciatura, de graduação plena. Brasília. Conselho Nacional de Educação, 2001. Disponível em: <http://portal.mec.gov.br/cne/arquivos/pdf/028.pdf.>. Acesso em: 12 maio 2016.

BRASIL. Ministério da Educação. Portaria no 552 SESu, de 25 de junho de 2007. Complemento ao art. $1^{\circ}, \S 2^{\circ}$ do Decreto Presidencial $n^{\circ} 6.096$, de 24 de abril de 2007. REUNI - Reestruturação e Expansão das Universidades Federais. Disponível em: <http://portal.mec.gov.br/sesu/arquivos/pdf/diretrizesreuni.pdf>. Acesso em: 12 maio 2016.

CORREIA, Wilson. REUNI: vamos continuar calados? Espaço Acadêmico, revista científica eletrônica da Universidade Estadual de Maringá, Paraná, n. 82, mar. 2008. Disponível em: <http://www.espacoacademico.com.br/082/82correia.htm.> Acesso em: 10 nov. 2015.

FREIRE, Paulo. Pedagogia da autonomia: saberes necessários à prática educativa. São Paulo: Paz e Terra, 1996.

LÉDA, Denise Bessa; MANCEBO, Deise. REUNI: heteronomia, precarização da universidade e do trabalho docente. Educação e Realidade, Porto Alegre, v. 34, p. 49-64, jan./abr. 2009.

LEHER, Roberto. A universidade reformada: atualidade para pensar tendências da educação superior 25 anos após sua publicação. Revista Contemporânea de Educação, v. 8, n. 16, ago./dez. 2013.

LIMA, Kátia Regina de Souza. Contrarreforma da educação nas Universidades Federais: o REUNI na UFF. Universidade e Sociedade, Brasília, v. 44, p. 147-157, 2009.

MAINARDES, Jefferson. Abordagem do ciclo de políticas: uma contribuição para a análise de políticas educacionais. Educação e Sociedade, Campinas, v. 27, n. 94, p. 47-69, jan./abr. 2006. Disponível em: <http://www.cedes.unicamp.br>. Acesso em: 23 jun. 2016.

MAZZONI, José Rafael. A reforma universitária e o ciclo básico. In: REUNIÃO ANUAL DA ASSOCIAÇÃO NACIONAL DE PÓS-GRADUAÇÃO EM EDUCAÇÃO - ANPED, 24.; 2001; Caxambu. Anais da... Caxambu: ANPEd, 2001.

MULHOLLAND, Timothy. O projeto UnB: universidade nova. Disponível em: <http://www.expandir.unb.br/Programa_mais_material_palestras.htm>. Acesso em: 19 ago. 2016.

NÓVOA, Antônio. Formação de professores e profissão docente. Os professores e a sua formação. Lisboa: Instituto de Inovação Educacional, 1992. p. 15-34. 
SACRISTÁN, José Gimeno. Poderes instáveis em educação. Porto Alegre: Artmed, 1999.

SCHÖN, Donald. Formar professores como profissionais reflexivos. Os professores e a sua formação. Lisboa: Instituto de Inovação Educacional, 1992. p. 77-92.

TARDIF, Maurice; LESSARD, Claude; LAHAYE, Louise. Os professores face ao saber: esboço de uma problemática do saber docente. Teoria e educação, Porto Alegre, n. 4, p. 215233, 1991.

TEIXEIRA, Carmen Fontes de Souza; COELHO, Maria Thereza Ávila Dantas; ROCHA, Marcelo Nunes Dourado. Bacharelado interdisciplinar: uma proposta inovadora na educação superior em saúde no Brasil. Ciência \& Saúde Coletiva, Rio de Janeiro, v. 18, n. 6, p. 163546, jun. 2013.

UNIVERSIDADE DE BRASÍLIA. Biblioteca Central. Plano orientador da Universidade de Brasília. Brasília, 1962.

UNIVERSIDADE FEDERAL DA BAHIA. Biblioteca Central. Universidade nova: reestruturação da arquitetura curricular da educação superior no Brasil. Salvador, 2006. Disponível em: 〈http://www.twiki.ufba.br/twiki/bin/view/UniversidadeNova/Apresentacao>. Acesso em: 19 ago. 2016.

UNIVERSIDADE FEDERAL DO SUL DA BAHIA. Biblioteca Central. Plano orientador Institucional e Político-Pedagógico. Itabuna, 2014. Disponível em: <http://ufsb.edu.br/wpcontent/uploads/2015/05/Plano-Orientador-UFSB-Final1.pdf>. Acesso em: 3 dez. 2015.

\footnotetext{
${ }^{\mathrm{i}}$ Sobre a autora

Eliana Povoas Pereira Estrela Brito

E-mail: eliana.povoasbrito@gmail.com / ORCID: http://orcid.org/0000-0002-4563-1354

Universidade Federal do Sul da Bahia - Brasil

Doutora em Educação pela Universidade Federal do Rio Grande do Sul [UFRGS]
} 